\title{
Circulation
}

\section{Folic Acid Improves Endothelial Function in Coronary Artery Disease via Mechanisms Largely Independent of Homocysteine Lowering}

Sagar N. Doshi, Ian F.W. McDowell, Stuart J. Moat, Nicola Payne, Hilary J. Durrant, Malcolm J. Lewis and Jonathan Goodfellow

Circulation. 2002;105:22-26

doi: $10.1161 / \mathrm{hc} 0102.101388$

Circulation is published by the American Heart Association, 7272 Greenville Avenue, Dallas, TX 75231

Copyright () 2002 American Heart Association, Inc. All rights reserved.

Print ISSN: 0009-7322. Online ISSN: 1524-4539

The online version of this article, along with updated information and services, is located on the World Wide Web at:

http://circ.ahajournals.org/content/105/1/22

Permissions: Requests for permissions to reproduce figures, tables, or portions of articles originally published in Circulation can be obtained via RightsLink, a service of the Copyright Clearance Center, not the Editorial Office. Once the online version of the published article for which permission is being requested is located, click Request Permissions in the middle column of the Web page under Services. Further information about this process is available in the Permissions and Rights Question and Answer document.

Reprints: Information about reprints can be found online at:

http://www.lww.com/reprints

Subscriptions: Information about subscribing to Circulation is online at:

http://circ.ahajournals.org//subscriptions/ 


\title{
Folic Acid Improves Endothelial Function in Coronary Artery Disease via Mechanisms Largely Independent of Homocysteine Lowering
}

\author{
Sagar N. Doshi, BSc, MBChB, MRCP; Ian F.W. McDowell, MD, MRCP, FRCPath; \\ Stuart J. Moat, BSc, PhD; Nicola Payne, BSc; Hilary J. Durrant, PhD, MBChB, MRCP; \\ Malcolm J. Lewis, PhD, DSc, FESC; Jonathan Goodfellow, BSc, MBBS, MRCP
}

Background-Homocysteine is a risk factor for coronary artery disease (CAD), although a causal relation remains to be proven. The importance of determining direct causality rests in the fact that plasma homocysteine can be safely and inexpensively reduced by $25 \%$ with folic acid. This reduction is maximally achieved by doses of $0.4 \mathrm{mg} / \mathrm{d}$. High-dose folic acid ( $5 \mathrm{mg} / \mathrm{d})$ improves endothelial function in CAD, although the mechanism is controversial. It has been proposed that improvement occurs through reduction in total (tHcy) or free (non-protein bound) homocysteine (fHcy). We investigated the effects of folic acid on endothelial function before a change in homocysteine in patients with CAD.

Methods and Results - A randomized, placebo-controlled study of folic acid (5 mg/d) for 6 weeks was undertaken in 33 patients. Endothelial function, assessed by flow-mediated dilatation (FMD), was measured before, at 2 and 4 hours after the first dose of folic acid, and after 6 weeks of treatment. Plasma folate increased markedly by 1 hour (200 compared with $25.8 \mathrm{nmol} / \mathrm{L} ; P<0.001$ ). FMD improved at 2 hours (83 compared with $47 \mu \mathrm{m} ; P<0.001$ ) and was largely complete by 4 hours (101 compared with $51 \mu \mathrm{m} ; P<0.001$ ). tHcy did not significantly differ acutely (4-hour tHcy, 9.56 compared with $9.79 \mu \mathrm{mol} / \mathrm{L} ; P=\mathrm{NS})$. fHcy did not differ at 3 hours but was slightly reduced at 4 hours (1.55 compared with 1.78 $\mu \mathrm{mol} / \mathrm{L} ; P=0.02)$. FMD improvement did not correlate with reductions in either fHcy or tHcy at any time.

Conclusions - These data suggest that folic acid improves endothelial function in CAD acutely by a mechanism largely independent of homocysteine. (Circulation. 2002;105:22-26.)

Key Words: risk factors $\boldsymbol{\square}$ plasma $\boldsymbol{m}$ coronary disease $\boldsymbol{\|}$ endothelium

E levated total plasma homocysteine (tHcy) is now an accepted and potentially modifiable risk factor for cardiovascular disease and death that appears to be largely independent of other conventional risk factors. ${ }^{1,2}$ However, it remains controversial as to whether the increased risk is mediated directly by homocysteine or whether homocysteine may simply be an epiphenomenon. ${ }^{3}$

Plasma homocysteine can be safely and inexpensively reduced by supplementation with oral B-group vitamins. Folic acid reduces total plasma homocysteine by $25 \%$ and is maximally achieved by doses of 0.4 to $0.5 \mathrm{mg}$ daily. ${ }^{4,5}$ This has led to the proposal that folic acid treatment may reduce cardiovascular risk by reducing tHcy.

Endothelial dysfunction is a key process in atherosclerosis ${ }^{6}$ and independently predicts cardiovascular events. ${ }^{7}$ High-dose folic acid (5 mg daily), alone or in combination with other B-group vitamins, can improve endothelial function in pa- tients with coronary artery disease $(\mathrm{CAD})$. However, the data are limited, and whether this improvement is due to a reduction in homocysteine or some other effect of folic acid is uncertain. ${ }^{8-10}$

We sought to investigate whether high-dose folic acid supplementation would improve endothelial dysfunction in patients with significant $\mathrm{CAD}$ who were taking standard therapy, independent of changes in homocysteine.

\section{Methods}

\section{Study Design}

The study was a randomized, double-blind, placebo-controlled, parallel design in which 33 patients were allocated to receive either $5 \mathrm{mg}$ daily folic acid (16 patients) or matched placebo (17 patients) for 6 weeks. Patients attended on 2 occasions separated by 6 weeks. All patients gave written informed consent, and the protocol conformed to the Declaration of Helsinki.

Received July 31, 2001; revision received October 16, 2001; accepted October 19, 2001

From the Cardiovascular Sciences Research Group, Wales Heart Research Institute, Departments of Pharmacology (S.N.D., M.J.L.), Biochemistry (I.F.W.M., S.J.M.), and Cardiology (J.G.), and the Department of Medical Computing and Statistics (N.P.), University of Wales College of Medicine, Heath Park, Cardiff, UK.

Correspondence to Dr J. Goodfellow, Wales Heart Research Institute, University of Wales College of Medicine, Heath Park, Cardiff CF14 4XN, UK. E-mail GoodfellowJ@ cardiff.ac.uk

(C) 2002 American Heart Association, Inc.

Circulation is available at http://www.circulationaha.org 


\section{Subjects}

Patients with CAD who were $<70$ years of age were recruited. We defined $\mathrm{CAD}$ as either angiographically proven coronary disease ( $\geq 50 \%$ luminal stenosis) or a history of myocardial infarction (creatinine kinase rise $>2$-fold normal with ECG changes). The level of plasma homocysteine was not an entry criterion. Patients were excluded if an acute coronary event had occurred $<3$ months before entry or if there was diabetes mellitus, uncontrolled hypertension, fasting plasma cholesterol $>6.5 \mathrm{mmol} / \mathrm{L}$, impaired renal function (creatinine $>120 \mu \mathrm{mol} / \mathrm{L}$ ), or clinically significant heart failure. Patients actively smoking or who had recently ceased smoking $(<6$ months), patients taking antioxidant vitamins (E or C), folic acid, or fish oils, and women taking hormone replacement were also excluded. All selected subjects were tested to exclude vitamin $B_{12}$ deficiency before entry, which precludes folic acid treatment.

\section{Study Protocol}

\section{Biochemical Parameters}

Lipids, glucose, creatinine, and $\mathrm{B}_{12}$ were analyzed on the day of sampling; other samples were separated and the serum/plasma stored at $-70^{\circ} \mathrm{C}$ until analysis. EDTA plasma for fHcy (non-protein bound) assay was deproteinized within 15 minutes of venepuncture before storage. EDTA plasma for tHcy assay was immediately separated by centrifuging before storage. At the first visit, venous blood was drawn before and at each hour for 4 hours after the first tablet for assay of plasma folate, fHcy, and tHcy. 5-Methyltetrahydrofolate (5-MTHF) was assayed in the folate group at baseline, 1 to 4 hours, and 6 weeks. Subjects were recumbent on a couch during the 4 hours after the first dose.

\section{Noninvasive Measurement of Endothelial Function}

Endothelial vasomotor function was assessed by flow-mediated dilatation (FMD), a nitric oxide-mediated process. ${ }^{11,12}$ FMD was measured by means of high-resolution ultrasound and wall-tracking, as previously described by us, after release of a cuff placed at the wrist, inflated for 5 minutes at $250 \mathrm{~mm} \mathrm{Hg} \cdot{ }^{13,14}$ FMD was taken as the greatest absolute increase in vessel end-diastolic diameter (EDD) during the first 3 minutes after cuff release. Vascular studies were performed by a single experienced operator in a temperaturecontrolled room $\left(21^{\circ}\right.$ to $\left.24^{\circ} \mathrm{C}\right)$ at the same time of day on patients fasted overnight. Medications were omitted on the morning of the visit, and nitrates were withheld for 24 hours before studies. Endothelium-independent dilation, in response to $400 \mu \mathrm{g}$ glyceryl trinitrate, was recorded at baseline, 4 hours, and 6 weeks. Blood pressure was measured continuously in the study arm by means of photophlethysmography (Finapres). Blood flow was calculated as the product of the Doppler time-velocity integral, heart rate, and brachial artery diameter measured by wall-tracking at that time. FMD was recorded before, at 2 and 4 hours after the first dose, and after 6 weeks of daily treatment.

\section{Biochemical Assays}

Lipids, glucose, and creatinine were assayed routinely. tHcy was measured by enzymatic immunoassay (Abbot IMx, Abbot Diagnostics) and $B_{12}$ was measured by competitive protein binding assays on an Elecys 2010 analyzer (Roche Diagnostics). Folate was measured by competitive binding assay with an IMx analyzer (Abbot Diagnostics). fHcy was measured by HPLC with fluorescence detection, with a modification of the technique described by Araki and Sako. ${ }^{15}$ 5-MTHF was measured by HPLC. ${ }^{16}$

\section{Withdrawals, Medication Changes, and Compliance}

All randomized patients completed the study. Other medications remained unchanged during the study period. No side effects were reported, and compliance assessed by a tablet count was $>98 \%$.
TABLE 1. Clinical Characteristics of Study Subjects

\begin{tabular}{|c|c|c|c|}
\hline Characteristic & $\begin{array}{r}\text { Placebo } \\
(n=17)\end{array}$ & $\begin{array}{l}\text { Folate } \\
(n=16)\end{array}$ & $P$ \\
\hline Age & $56 \pm 7$ & $55 \pm 7$ & NS \\
\hline Male:female & $16 / 1$ & $14 / 2$ & NS \\
\hline Height, m & $1.73 \pm 0.05$ & $1.71 \pm 0.07$ & NS \\
\hline Weight, kg & $81.2 \pm 12$ & $89.9 \pm 13$ & NS \\
\hline Angiographic CAD & $16(94.1)$ & $16(100)$ & NS \\
\hline Myocardial infarction & $10(58.8)$ & $9(56.3)$ & NS \\
\hline $\begin{array}{l}\text { Revascularization (CABG or } \\
\text { PTCA) }\end{array}$ & $15(88.3)$ & $13(81.3)$ & NS \\
\hline Hypertension & $7(41.2)$ & $5(31.3)$ & NS \\
\hline Family history $<60$ y & $11(64.7)$ & $9(56.3)$ & NS \\
\hline Smoking history & $13(81.3)$ & $10(58.8)$ & NS \\
\hline Cerebrovascular event & $1(5.9)$ & $0(0)$ & NS \\
\hline Peripheral vascular disease & $1(5.9)$ & $1(6.3)$ & NS \\
\hline Angina & $2(11.8)$ & $2(12.5)$ & NS \\
\hline Antiplatelet therapy & $15(88.3)$ & $16(100)$ & NS \\
\hline Lipid-lowering therapy & $16(94.1)$ & $16(100)$ & NS \\
\hline Statin & $14(82.4)$ & $14(87.5)$ & NS \\
\hline Fibrate & $3(17.6)$ & $3(18.8)$ & NS \\
\hline \multicolumn{4}{|l|}{ Other drug therapy } \\
\hline$\beta$-Blocker & $10(58.8)$ & $6(37.5)$ & NS \\
\hline ACE inhibitor & $1(5.9)$ & $1(6.3)$ & NS \\
\hline Calcium channel blocker & $2(11.8)$ & $3(18.8)$ & NS \\
\hline ATII receptor blocker & $0(0)$ & $1(6.3)$ & NS \\
\hline Nitrate & $2(11.8)$ & $1(6.3)$ & NS \\
\hline
\end{tabular}

ATII receptor blocker indicates angiotensin II receptor antagonist.

Data are presented as mean \pm SD or patient numbers and percentages in parentheses.

\section{Statistical Analysis}

Results are expressed as mean \pm SD unless otherwise stated. The main statistical analysis of the folic acid study was analyzed by ANCOVA. The associations between changes in FMD and tHcy, fHcy, plasma folate, and 5-MTHF were assessed by Spearman rank correlation analysis. A value of $P<0.05$ was considered statistically significant. We calculated that 18 subjects would be required to detect an improvement in FMD from $40 \mu \mathrm{m}$ (SD, $20 \mu \mathrm{m})$ to $80 \mu \mathrm{m}$ $(\mathrm{SD}, 30 \mu \mathrm{m})$ in the intervention group, with $90 \%$ power at the $5 \%$ significance level.

\section{Results}

\section{Baseline Characteristics}

The study comprised 33 patients (30 men and 3 women). There were no significant differences in baseline clinical or biochemical parameters (Tables 1 and 2).

\section{Effects on FMD and Vascular Measurements}

FMD was impaired in both groups at baseline compared with published normal values (folic acid, 1.26 $\pm 0.75 \%$ EDD; placebo, 1.14 $\pm 0.62 \%$ EDD) (Table 3). ${ }^{17}$ After folic acid, FMD improved markedly at 2 and 4 hours after the first dose (Figure 1), with small additional improvement after 6 weeks of daily treatment compared with the change at 4 hours (FMD, 111 compared with $101 \mu \mathrm{m} ; P=0.04$ ). There was no significant difference between the glyceryl trinitrate response 
TABLE 2. Biochemical Parameters at Baseline and 6 Weeks

\begin{tabular}{|c|c|c|c|c|c|c|}
\hline \multirow[b]{2}{*}{ Variable } & \multicolumn{3}{|c|}{ Baseline } & \multicolumn{3}{|c|}{6 wk } \\
\hline & $\begin{array}{r}\text { Placebo } \\
(n=17)\end{array}$ & $\begin{array}{l}\text { Folate } \\
(n=16)\end{array}$ & $P^{*}$ & $\begin{array}{r}\text { Placebo } \\
(n=17)\end{array}$ & $\begin{array}{l}\text { Folate } \\
(n=16)\end{array}$ & $P \dagger$ \\
\hline Plasma folate, $\mathrm{nmol} / \mathrm{L}$ & $26.09 \pm 6.8$ & $22.37 \pm 8.7$ & NS & $26.8 \pm 5.6$ & $604.22 \pm 429$ & $<0.001$ \\
\hline Total homocysteine, $\mu \mathrm{mol} / \mathrm{L}$ & $10.8 \pm 2.2$ & $10.6 \pm 2.6$ & NS & $10.8 \pm 2.1$ & $8.3 \pm 1.3$ & $<0.001$ \\
\hline Free homocysteine, $\mu \mathrm{mol} / \mathrm{L}$ & $1.99 \pm 0.47$ & $2.05 \pm 0.49$ & NS & $1.84 \pm 0.38$ & $1.46 \pm 0.34$ & $<0.001$ \\
\hline Vitamin $\mathrm{B}_{12}, \mathrm{pmol} / \mathrm{L}$ & $312 \pm 105$ & $306 \pm 73$ & NS & $326 \pm 97$ & $327 \pm 81$ & NS \\
\hline Cholesterol, mmol/L & $4.47 \pm 0.57$ & $4.36 \pm 0.87$ & NS & $4.3 \pm 0.58$ & $4.62 \pm 0.84$ & 0.01 \\
\hline HDL cholesterol, mmol/L & $1.16 \pm 0.36$ & $1.08 \pm 0.2$ & NS & $1.16 \pm 0.42$ & $1.09 \pm 0.23$ & NS \\
\hline LDL cholesterol, mmol/L & $2.65 \pm 0.48$ & $2.7 \pm 0.77$ & NS & $2.41 \pm 0.47$ & $2.74 \pm 0.83$ & NS \\
\hline Triglycerides, mmol/L & $1.45 \pm 0.7$ & $1.43 \pm 0.45$ & NS & $1.69 \pm 1.21$ & $1.73 \pm 0.84$ & NS \\
\hline Glucose, mmol/L & $5.49 \pm 0.75$ & $5.6 \pm 0.77$ & NS & $5.52 \pm 0.72$ & $5.61 \pm 0.93$ & NS \\
\hline Creatinine, $\mu \mathrm{mol} / \mathrm{L}$ & $95.1 \pm 12.1$ & $98.7 \pm 18.1$ & NS & $92.8 \pm 11.4$ & $95.2 \pm 14.5$ & NS \\
\hline
\end{tabular}

at baseline and at 4 hours and 6 weeks. Heart rate, blood pressure, brachial artery EDD, and baseline and peak hyperemic flow did not differ significantly after folic acid.

\section{Effects on Biochemical Parameters}

Plasma folate in the treatment group increased markedly by 1 hour and remained elevated at 2, 3, and 4 hours and at 6 weeks (Figure 2). tHcy fell in both groups during the initial 4 hours. There were no significant differences between tHcy levels during the 4 hours after the first dose of folic acid, but tHcy was significantly decreased after 6 weeks of treatment (Figure 3). fHcy (non-protein bound) fell in both groups but was not significantly altered during the first 3 hours after folic acid. fHcy was significantly reduced at 4 hours and 6 weeks (Figure 4). 5-MTHF increased from a baseline of 22.1 to 132.1 at 4 hours and $305.7 \mathrm{nmol} / \mathrm{L}$ at 6 weeks in the folate group (Figure 5). Vitamin $\mathrm{B}_{12}$, HDL, LDL, triglycerides, glucose, and creatinine were unchanged by folic acid after 6 weeks. Cholesterol was marginally higher in the folic acid group and lower in the placebo group at 6 weeks (Table 2).

\section{Correlates of Improved FMD}

In univariate analysis, the change in FMD did not correlate with either tHcy or fHcy reduction or with folate or 5-MTHF increase at any point of the intervention ( 2 or 4 hours or 6 weeks; $P=\mathrm{NS}$ ).

\section{Discussion}

The present study confirms and extends the findings of recent studies demonstrating improved endothelial function in patients with CAD taking high-dose folic acid (5 mg daily for 1.5 to 4 months) alone or in combination with other B-group vitamins. ${ }^{8-10}$

The mechanism underlying this improvement is controversial and has been previously attributed to reductions in either tHcy or fHcy that occur with folate therapy. ${ }^{8,9}$ The present

TABLE 3. Vascular Data at Baseline, 2 and 4 hours After the First Dose of Folic Acid and Placebo, and After 6 Weeks of Daily Treatment

\begin{tabular}{|c|c|c|c|c|c|c|c|c|c|c|c|c|}
\hline Variable & $\begin{array}{l}\text { Baseline } \\
\text { Folate } \\
(\mathrm{n}=16)\end{array}$ & $\begin{array}{c}\text { Baseline } \\
\text { Placebo } \\
(n=17)\end{array}$ & $P^{*}$ & $\begin{array}{c}2-h \\
\text { Folate } \\
(n=16)\end{array}$ & $\begin{array}{c}2-h \\
\text { Placebo } \\
(n=17)\end{array}$ & $P \dagger$ & $\begin{array}{c}\text { 4-h } \\
\text { Folate } \\
(n=16)\end{array}$ & $\begin{array}{c}\text { 4-h } \\
\text { Placebo } \\
(n=17)\end{array}$ & $P \ddagger$ & $\begin{array}{l}\text { 6-wk } \\
\text { Folate } \\
(n=16)\end{array}$ & $\begin{array}{c}\text { 6-wk } \\
\text { Placebo } \\
(n=17)\end{array}$ & $P \S$ \\
\hline Vessel EDD, mm & $4.29 \pm 0.7$ & $4.20 \pm 0.5$ & NS & $4.29 \pm 0.7$ & $4.21 \pm 0.5$ & NS & $4.29 \pm 0.6$ & $4.19 \pm 0.5$ & NS & $4.27 \pm 0.7$ & $4.18 \pm 0.5$ & NS \\
\hline $\mathrm{FMD}, \mu \mathrm{m}$ & $52.5 \pm 29$ & $48 \pm 24$ & NS & $83 \pm 33$ & $47 \pm 23$ & $<0.001$ & $100 \pm 35$ & $51 \pm 20$ & $<0.001$ & $111 \pm 28$ & $52 \pm 19$ & $<0.001$ \\
\hline $\begin{array}{l}\text { GTN diameter } \\
\text { change, } \mu \mathrm{m}\end{array}$ & $415 \pm 52$ & $396 \pm 63$ & NS & & & & $419 \pm 62$ & $409 \pm 53$ & NS & $431 \pm 37$ & $402 \pm 60$ & NS \\
\hline $\begin{array}{l}\text { Baseline blood flow, } \\
\mathrm{mL} / \mathrm{min}\end{array}$ & $35 \pm 15$ & $37 \pm 18$ & NS & $35 \pm 5$ & $35 \pm 14$ & NS & $34 \pm 11$ & $33 \pm 12$ & NS & $34 \pm 13$ & $33 \pm 12$ & NS \\
\hline $\begin{array}{l}\text { Peak hyperemic } \\
\text { flow, } \mathrm{mL} / \mathrm{min}\end{array}$ & $180 \pm 67$ & $189 \pm 54$ & NS & $184 \pm 60$ & $192 \pm 54$ & NS & $186 \pm 49$ & $191 \pm 55$ & NS & $186 \pm 52$ & $189 \pm 55$ & NS \\
\hline Heart rate, bpm & $58 \pm 8$ & $61 \pm 11$ & NS & $58 \pm 8$ & $60 \pm 10$ & NS & $59 \pm 8$ & $62 \pm 11$ & NS & $59 \pm 8$ & $62 \pm 12$ & NS \\
\hline $\begin{array}{l}\text { Systolic blood } \\
\text { pressure, } \mathrm{mm} \mathrm{Hg}\end{array}$ & $133 \pm 18$ & $131 \pm 15$ & NS & $133 \pm 18$ & $129 \pm 14$ & NS & $133 \pm 18$ & $131 \pm 15$ & NS & $133 \pm 19$ & $130 \pm 13$ & NS \\
\hline $\begin{array}{l}\text { Diastolic blood } \\
\text { pressure, } \mathrm{mm} \mathrm{Hg}\end{array}$ & $71 \pm 6$ & $75 \pm 10$ & NS & $72 \pm 7$ & $74 \pm 10$ & NS & $71 \pm 7$ & $74 \pm 9$ & NS & $70 \pm 9$ & $72 \pm 9$ & NS \\
\hline
\end{tabular}

GTN indicates glyceryl trinitrate.

Data are presented as mean \pm SD. Comparing changes on folic acid with changes on placebo at baseline, ${ }^{\star} 2$ hours, $\uparrow 4$ hours, $\neq$ and 6 weeks. $\S$ 


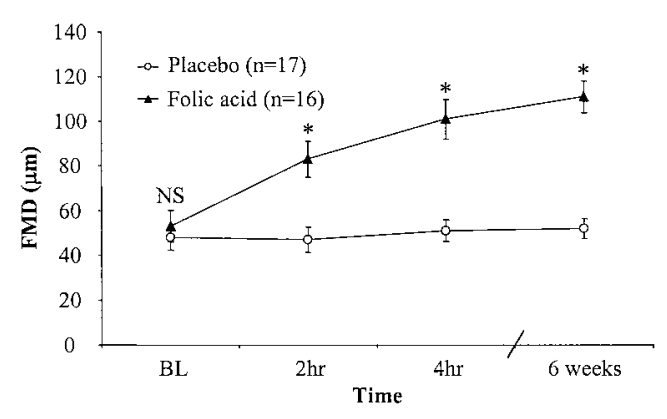

Figure 1. FMD before, at 2 and 4 hours after first dose, and after 6 weeks of folic acid ( $5 \mathrm{mg}$ daily) or placebo. Data are presented as mean \pm SEM. FMD was defined as the greatest (absolute) increase in EDD during the first 3 minutes after cuff release. ${ }^{\star} P<0.001$, comparing change on folic acid with change on placebo.

study, however, provides new evidence indicating that homocysteine reduction is unlikely to account for the acute and possibly the chronic improvement observed with folic acid.

Improvement in endothelial function was observed acutely after the first oral dose of folic acid and before any significant reduction in tHcy. tHcy fell in both groups in the acute phase, an effect that has been previously noted and due to reduction in plasma albumin induced by supine posture. ${ }^{18}$ Interestingly, despite a large fall in tHcy in the placebo group $(9.8 \pm 3.9 \%$ at 4 hours), no change in endothelial function was observed. This observation strengthens the conclusion that improved endothelial function in the folate group was not mediated by the similar reduction in tHcy in the acute phase. Furthermore, no correlation was found between FMD improvement and tHcy reduction at any time point. At 6 weeks, tHcy was significantly reduced by folic acid, with only a small further improvement in FMD compared with the effect at 4 hours (111 compared with $101 \mu \mathrm{m} ; P=0.042)$. This finding is consistent with some additional improvement conferred by tHcy reduction at 6 weeks but may be explained by enhancement after long-term folic acid treatment.

Improvement in FMD also occurred before a significant fall in fHcy, indicating that enhancement was also not explained by reduction in fHcy. Furthermore, no correlation

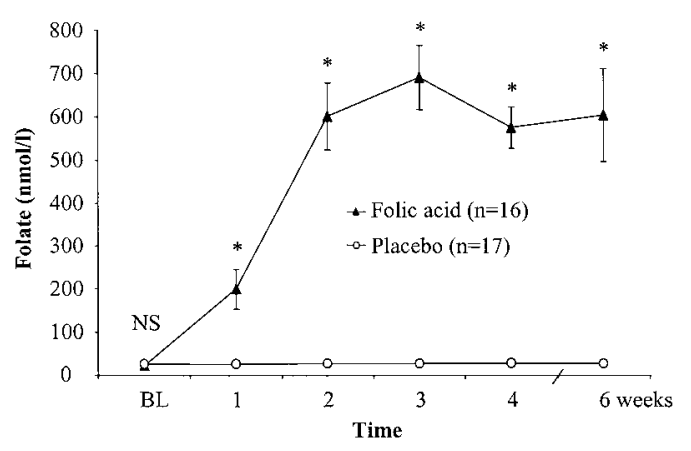

Figure 2. Time course of plasma folate after first dose of placebo or folic acid $(5 \mathrm{mg})$ and after 6 weeks of treatment (mean \pm SEM). Plasma folate was increased to supraphysiological levels at 1 hour and remained so at all subsequent times. ${ }^{*} P<0.001$, comparing change on folic acid with change on placebo.

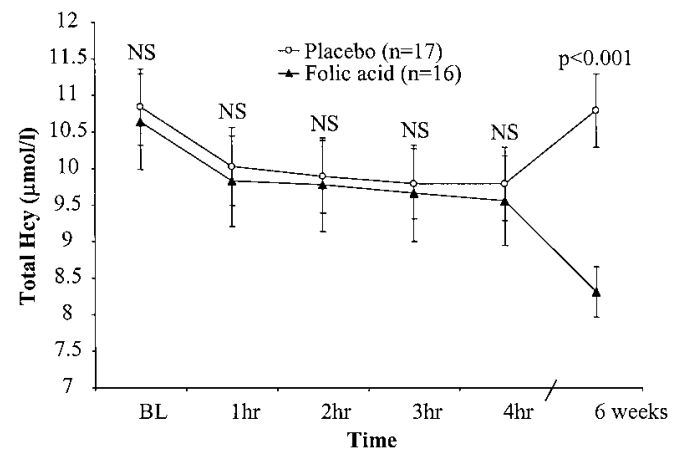

Figure 3. Time course of thcy after first dose of placebo or folic acid $(5 \mathrm{mg})$ and after 6 weeks of treatment (mean \pm SEM). tHcy fell in both groups due to recumbent posture but did not significantly differ for initial 4 hours. By 6 weeks tHcy was significantly lower in the folic acid group. $P<0.001$, comparing change on folic acid with change on placebo.

was found between improvement in FMD and reduction in fHcy at any time.

Levels of plasma folate were increased to supraphysiological levels $(>45.3 \mathrm{nmol} / \mathrm{L})$ by 1 hour and remained elevated thereafter. Under normal conditions, the majority $(>80 \%)$ of circulating folate exists as the metabolically active form, 5-MTHF. Plasma 5-MTHF is increased acutely after folic acid loading. ${ }^{19}$ Levels were supraphysiological by 1 hour after folic acid and were further increased at 6 weeks compared with the 4-hour level. The mechanism behind this increase is unclear but in part may be explained by induction of dihydrofolate reductase, the enzyme responsible for the initial step in the conversion of folic acid to 5-MTHF. Such induction has been observed with methotrexate in vitro after 48 hours. ${ }^{20}$ Whatever the mechanism, the increased level of 5-MTHF at 6 weeks may account for the further improvement in endothelial function observed at 6 weeks.

It is likely that the majority of improvement in endothelial function observed in the present study is due to direct pharmacological actions of folic acid rather than reductions in tHcy or fHcy. It is important to stress that plasma folate levels observed in this study cannot be achieved by dietary fortification with folic acid (up to $0.665 \mathrm{mg} / \mathrm{d})^{21}$ or low-dose $(0.4$ $\mathrm{mg}$ ) folic acid supplementation. ${ }^{5}$ Plausible mechanisms exist

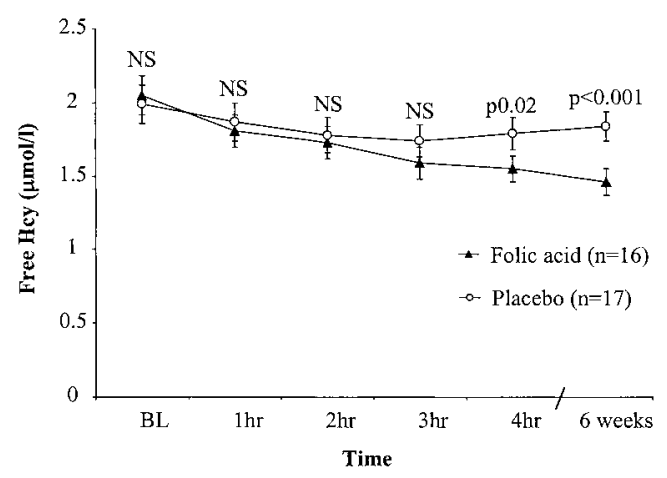

Figure 4. Time course of fHcy after first dose of placebo or folic acid $(5 \mathrm{mg})$ and after 6 weeks of treatment (mean \pm SEM). fHcy fell in both groups due to a recumbent posture but did not significantly differ for the initial 3 hours. fHcy was significantly lower at 4 hours and 6 weeks after folic acid. 


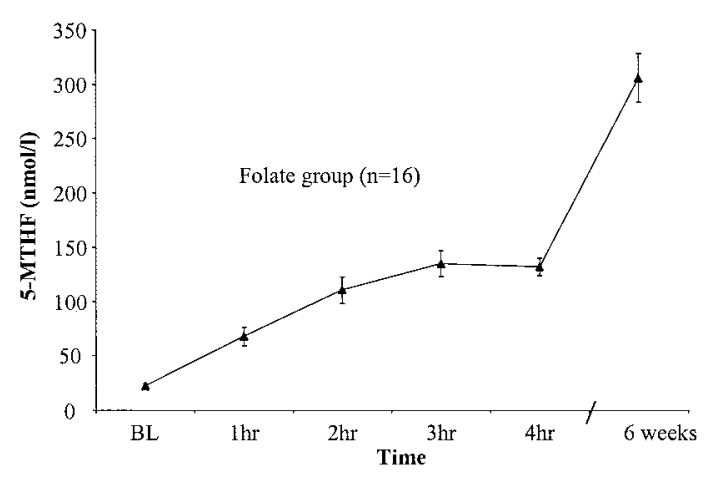

Figure 5. Time course of 5-MTHF change in the folate group (mean \pm SEM). 5-MTHF was elevated to supraphysiological levels by 1 hour. By 6 weeks, levels were further increased compared with 4-hour level and possibly explained in part by induction of dihydrofolate reductase.

to explain how folic acid may acutely enhance endothelial function independent of homocysteine. In vitro, 5-MTHF has intrinsic antioxidant actions, can increase nitric oxide production by endothelial nitric oxide synthase, and, furthermore, can reduce superoxide production by endothelial nitric oxide synthase in the setting of reduced cofactor tetrahydrobiopterin $\left(\mathrm{BH}_{4}\right)$ bioavailability. ${ }^{22,23}$ In vivo, the intra-arterial infusion of 5-MTHF will acutely improve endothelial function in familial hypercholesterolemia ${ }^{23}$ and $\mathrm{CAD}^{10}$ without lowering homocysteine. Similarly, the effects of methionine loading $(100 \mathrm{mg} / \mathrm{kg})$, which increases plasma homocysteine and acutely impairs endothelial function, ${ }^{24}$ is abrogated by simultaneous administration of folic acid $(20 \mathrm{mg})$ without alteration of homocysteine increase. ${ }^{25}$

\section{Implications of the Study}

These data show that improved endothelial function observed with high-dose folic acid in CAD occurs acutely and is independent of changes in either tHcy or fHcy. It seems probable that this occurs largely by direct mechanisms other than through homocysteine reduction. The homocysteinereducing effect of folic acid in CAD is maximal at $0.4 \mathrm{mg}$ in patients with normal renal function. ${ }^{5}$ However, if homocysteine lowering is not the major mechanism of benefit of high-dose folic acid, on-going outcome studies with moderate doses of folate in patients with cardiovascular disease $(0.8$ to $2.5 \mathrm{mg})^{26}$ may not reveal benefit despite lowering homocysteine. This may reflect the lower doses of folate used, and this point should be borne in mind when interpreting the results of these studies.

\section{Acknowledgments}

Dr Doshi is supported by a Junior Research Fellowship from the British Heart Foundation. The authors appreciate the donation of folic acid and matched placebo by Dr A.S. Burbage of Peter Black Healthcare Ltd and thank J. Chapman for laboratory assistance, Z.E. Clark for homocysteine and folate assays, and R.D. Ellis for B12 assays.

\section{References}

1. Boushey CJ, Beresford SA, Omenn GS, et al. A quantitative assessment of plasma homocysteine as a risk factor for vascular disease: probable benefits of increasing folic acid intakes. JAMA. 1995;274:1049-1057.
2. Anderson JL, Muhlestein JB, Horne BD, et al. Plasma homocysteine predicts mortality independently of traditional risk factors and C-reactive protein in patients with angiographically defined coronary artery disease. Circulation. 2000;102:1227-1232.

3. Scott JM. Homocysteine and cardiovascular risk. Am J Clin Nutr. 2000; 72:333-334.

4. Homocysteine Lowering Trialists' Collaboration. Lowering blood homocysteine with folic acid based supplements: meta-analysis of randomised trials. BMJ. 1998;316:894-898.

5. Lobo A, Naso A, Arheart K, et al. Reduction of homocysteine levels in coronary artery disease by low-dose folic acid combined with vitamins B6 and B12. Am J Cardiol. 1999;83:821-825.

6. Ross R. The pathogenesis of atherosclerosis: a perspective for the 1990s. Nature. 1993;362:801-809.

7. Schachinger V, Britten MB, Zeiher AM. Prognostic impact of coronary vasodilator dysfunction on adverse long-term outcome of coronary heart disease. Circulation. 2000;101:1899-1906.

8. Title LM, Cummings PM, Giddens K, et al. Effect of folic acid and antioxidant vitamins on endothelial dysfunction in patients with coronary artery disease. J Am Coll Cardiol. 2000;36:758-765.

9. Chambers JC, Ueland PM, Obeid OA, et al. Improved vascular endothelial function after oral B vitamins: an effect mediated through reduced concentrations of free plasma homocysteine. Circulation. 2000;102: 2479-2483.

10. Doshi SN, McDowell IF, Moat SJ, et al. Folate improves endothelial function in coronary artery disease: an effect mediated by reduction of intracellular superoxide? Arterioscler Thromb Vasc Biol. 2001;21: 1196-1202.

11. Doshi SN, Naka KK, Ashton M, et al. Flow-mediated dilatation following wrist and upper arm occlusion in humans: the contribution of nitric oxide. Clin Sci (Colch). 2001;101:629-635.

12. Joannides R, Haefeli WE, Linder L, et al. Nitric oxide is responsible for flow-dependent dilatation of human peripheral conduit arteries in vivo. Circulation. 1995;91:1314-1319.

13. Goodfellow J, Bellamy MF, Ramsey MW, et al. Dietary supplementation with marine omega-3 fatty acids improves systemic large artery endothelial function in subjects with hypercholesterolemia. J Am Coll Cardiol. 2000;35:265-270.

14. Ramsey MW, Goodfellow J, Jones CJ, et al. Endothelial control of arterial distensibility is impaired in chronic heart failure. Circulation. 1995;92:3212-3219.

15. Araki A, Sako Y. Determination of free and total homocysteine in human plasma by high-performance liquid chromatography with fluorescence detection. J Chromatogr. 1987;422:43-52.

16. Leeming RJ, Pollock A, Melville LJ, Hamon CG. Measurement of 5-methyltetrahydrofolic acid in man by high-performance liquid chromatography. Metabolism. 1990;39:902-904.

17. Adams MR, Robinson J, Sorensen K, et al. Normal ranges for brachial artery flow-mediated dilatation: a non-invasive ultrasound test of arterial endothelial function. J Vasc Invest. 1996;2:146-150.

18. Powers HJ, Moat SJ. Developments in the measurement of plasma total homocysteine. Curr Opin Clin Nutr Metab Care. 2000;3:391-397.

19. Kelly P, McPartlin J, Goggins M, et al. Unmetabolized folic acid in serum: acute studies in subjects consuming fortified food and supplements. Am J Clin Nutr. 1997;65:1790-1795.

20. Eastman HB, Swick AG, Schmitt MC, et al. Stimulation of dihydrofolate reductase promoter activity by antimetabolic drugs. Proc Natl Acad Sci U S A. 1991;88:8572-8576.

21. Malinow MR, Duell PB, Hess DL, et al. Reduction of plasma homocys$\mathrm{t}(\mathrm{e})$ ine levels by breakfast cereal fortified with folic acid in patients with coronary heart disease. $N$ Engl J Med. 1998;338:1009-1015.

22. Stroes ES, van Faassen EE, Yo M, et al. Folic acid reverts dysfunction of endothelial nitric oxide synthase. Circ Res. 2000;86:1129-1134.

23. Verhaar MC, Wever RM, Kastelein JJ, et al. 5-methyltetrahydrofolate, the active form of folic acid, restores endothelial function in familial hypercholesterolemia. Circulation. 1998;97:237-241.

24. Bellamy MF, McDowell IF, Ramsey MW, et al. Hyperhomocysteinemia after an oral methionine load acutely impairs endothelial function in healthy adults. Circulation. 1998;98:1848-1852.

25. Usui M, Matsuoka H, Miyazaki H, et al. Endothelial dysfunction by acute hyperhomocyst(e)inaemia: restoration by folic acid. Clin Sci (Colch). 1999;96:235-239.

26. Clarke R, Armitage J. Vitamin supplements and cardiovascular risk: review of the randomized trials of homocysteine-lowering vitamin supplements. Semin Thromb Hemost. 2000;26:341-348. 